\title{
How to determine the amount of levator resection in congenital ptosis repair
}

\section{Abstract}

Background and objective: Levator aponeurosis resection is an effective technique to correct blepharoptosis when the levator function is fair to good. This study aimed to determine the amount of levator resection in congenital blepharoptosis repair.

Methods: This is a prospective case series study conducted in Rizgary teaching hospital and private hospitals in Erbil city, Kurdistan Region, Iraq, from June 2011 to August 2019. The data of 53 patients (64 eyelids) affected by congenital blepharoptosis with poor to good levator function that underwent unilateral orbilateral levator resection blepharoptosis repair through the standard approach were included. The final outcome measures included postoperative eyelid height, contour, and symmetry.

Results: This study includes a total of 53 patients with congenital blepharoptosis (64 eyelids); 20 males and 33 females. The age of the patients ranged from 3 years to 54 years, with a mean age \pm SD of $14.11 \pm 10.66$ years. The ptosis was right sided in 22 patients (41.5\%), left sided in 20 patients $(37.7 \%)$, and bilateral in 11 patients $(20.8 \%)$. The study showed good patient satisfaction in $66.03 \%$ of the cases, suboptimal satisfaction in $22.64 \%$ of the cases, and poor satisfaction in $11.32 \%$ of the cases.

Conclusion: The levator resection for congenital ptosis is effective even with poor levator function and replaced in our practice the traditional fascial sling. We recommend that further studies be done on a larger number of patients to investigate the effectiveness of levator resection in patients with severe ptosis and very poor levator function.

Keywords: Congenital blepharoptosis; Levator aponeurosis; Levator resection.

\section{Introduction}

Ptosis of the upper eyelid, blepharoptosis, is defined as an abnormally low-positioned upper eyelid margin in the primary gaze position, which results in narrowing of the palpebral fissure and opening. The normal position of the upper eyelid margin is 1 to 2 $\mathrm{mm}$ below the superior corneal limbus in the primary gaze position. ${ }^{1}$ Ptosis is considered congenital if present at birth or diagnosed within the first year of life. Congenital ptosis is generally unilateral $(70 \%)$, but maybe bilateral. It can be isolated or associated with diseases of one or more of the extraocular muscles and/or other systemic conditions. A thorough understanding of the anatomy of the upper eyelid and surrounding structures is mandatory to achieve satisfactory surgical results and avoid potential complications. ${ }^{2}$ The available histologic data appear to support the classification of congenital blepharoptosis as dysgenesis rather than dystrophy. ${ }^{3}$ Congenital ptosis may be associated with visual disturbances in addition to being a cosmetic problem. Early correction is usually indicated to prevent amblyopia. ${ }^{4}$ The patient's condition should first be assessed to determine whether or not significant ptosis exists. If it does exist, a few questions will determine whether it is congenital or acquired. If it is acquired, the cause may be revealed by questioning, examination, and perhaps medical and neurological consultation. The ophthalmological consultation is essential

${ }^{1}$ Rizgary Teaching Hospital, Erbil, I raq

2 Department of Surgery, College of Medicine, Hawler Medical University, Erbil, I raq.

* Correspondence: muhamed.erbil@gmail.com 
to assess the vision. ${ }^{5}$ The most important measurements to be made are the amount of ptosis in the primary position and the amount of levator function. Ptosis can be divided conveniently into three categories; mild, moderate, and severe. A ptosis of 2 $\mathrm{mm}$ or less is mild, of approximately $3 \mathrm{~mm}$ is moderate, and of $4 \mathrm{~mm}$ or more is severe. The amount of levator function is determined by measuring the eyelid excursion as it moves from the eyes-down position to the eyes-up position with the frontalis function abolished. Normally the upper eyelid excursion measures from 13 to $16 \mathrm{~mm}$. Levator function can be classified as good ( 8 to $16 \mathrm{~mm}$.), fair (5 to 7 $\mathrm{mm}$.), or poor (4 mm. or less). ${ }^{6}$ Resection and resection of the levator aponeurosis is the technique that is often used in the correction of ptosis in patients with greater than $5 \mathrm{~mm}$ of levator function. ${ }^{7}$ This study aimed to evaluate the levator resection for correction of congenital ptosis and determine the amount of levator resection in congenital blepharoptosis repair.

\section{Methods}

Design and sample collection: This is a prospective case series study conducted at Rizgary hospital and private hospitals in Erbil city, Kurdistan region-Iraq from June 2011 to August 2019. A total sample of 53 patients with congenital ptosis treated with levator resection was included in this study. Their age ranged from 3 to 54 years. All patients underwent levator resection and were evaluated clinically and photographically before and after the operation.

Exclusion criteria: Exclusion criteria include any patient with a hematological disease, patients on an anticoagulant, and any patient with psychological disease. Two patients were excluded because of a lack of follow up.

Procedure: Preoperative planning is critical when performing levator resection. During the preoperative consultation, we assessed the type of ptosis, the severity of ptosis, the amount of levator function, the Bells phenomenon, and the frontalis excursion. Ophthalmological consultation was done. Medications and allergies were reviewed. The patient was instructed to stop all medications that interfere with the platelet function, if any, two weeks prior to surgery and can restart them one week after the procedure. Appropriate laboratory tests were obtained. The proposed amount of levator resection was determined preoperatively based on the severity of the ptosis and the amount of levator function and rechecked intraoperatively in alert patients. The outcomes and possible complications have been discussed with patients or parents, and the informed consent was signed by them. Preoperative photos have been taken. Preoperative marking was done in a standing position. The operation was done under general anesthesia for patients less than 18 years (42 patients) and Local anesthesia for older patients (11 patients). Scrubbing was done, and the patient was prepped. Local infiltration along the marking was done with lidocaine $2 \%$ and adrenaline in the concentration (1 in 100,000). After waiting for 7 to 10 minutes, the eye shield was immersed in tetracycline eye ointment, or gentamycin eye ointment was placed to protect the eye. A skin incision was made along the marking. The dissection is carried through the Orbicularis Oculi muscle. A skin muscle flap was dissected superiorly, exposing the point of fusion of the levator with the septum. The septum was cut completely, exposing the preaponeurotic fat beneath the septum. Dissection continued superiorly posterior to the fat until the Whitnall ligament was exposed. The superior tarsal border was exposed, and the levator aponeurosis was then dissected off the superior aspect of the tarsus. The inferior edge of the aponeurosis was grasped and dissected off Muller's muscle up to the Whitnall ligament using Colorado needle tip cautery. Cut the medial and lateral horns of the levator aponeurosis. The inferior border of levator aponeurosis was grasped by two 
https:/ / doi.org/ 10.15218/ zjms.2021.002

toothed forceps and pulled over the tarsal plate (Figure 1), and released to lie on the tarsal plate. Then, the points of new attachments of levator muscle to the superior border of tarsus was marked (Figure 2).
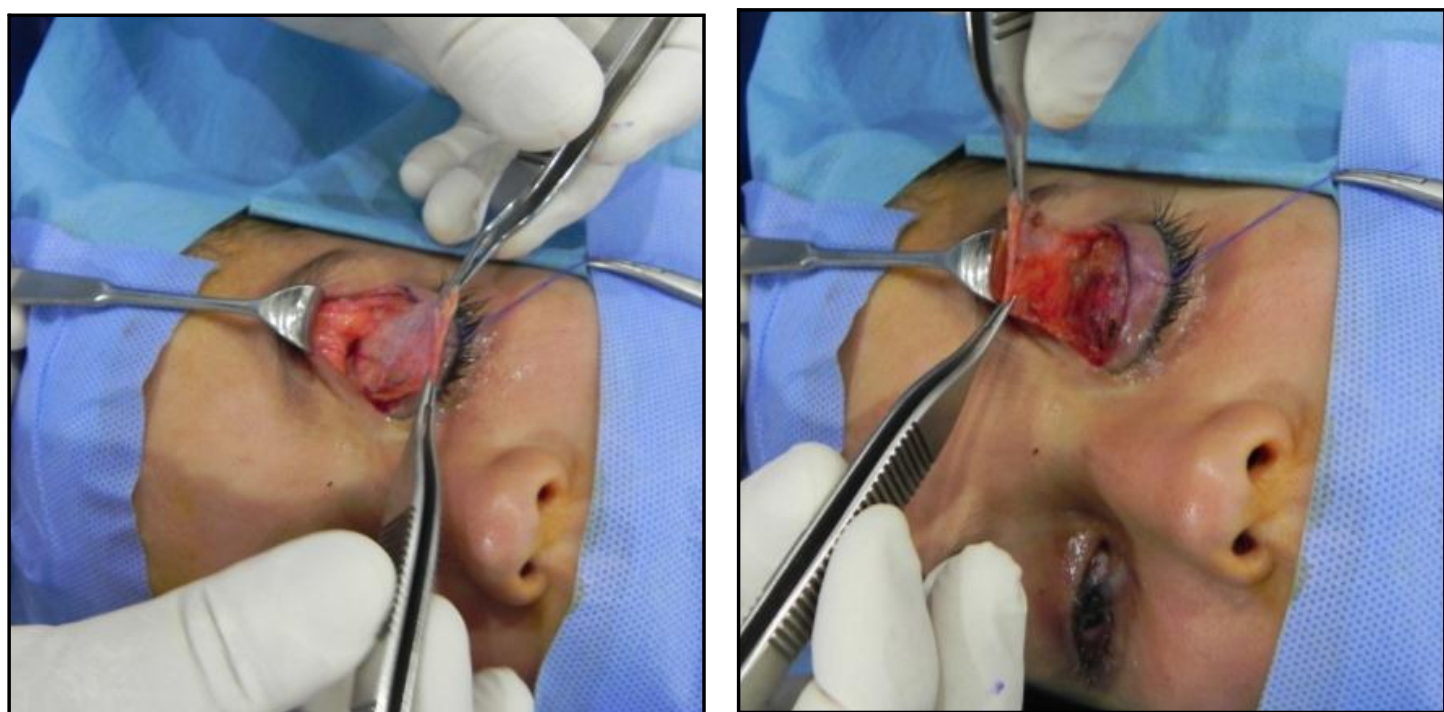

Figure 1: The levator aponeurosis is dissected off the inferior, medial, and lateral attachments.
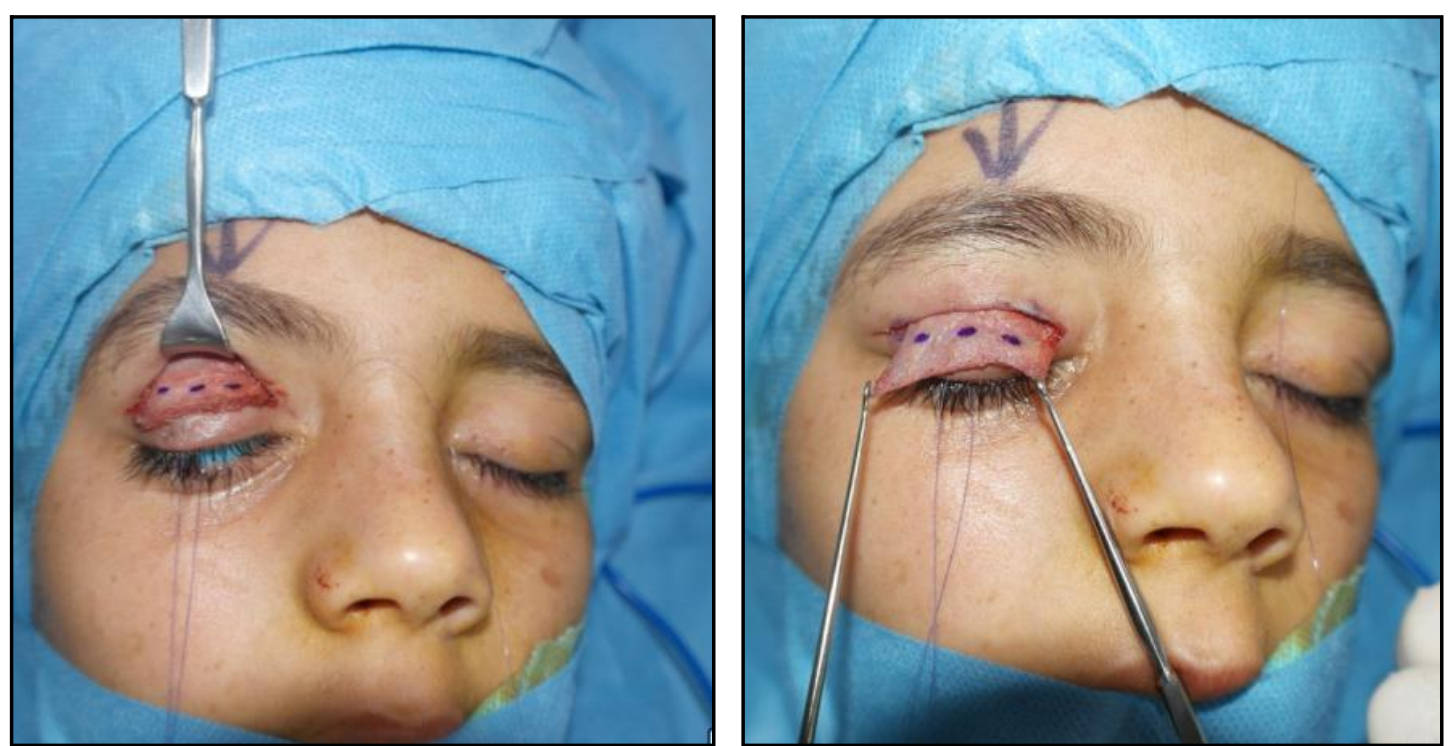

Figure 2: The inferior border of levator aponeurosis is grasped by two toothed forceps and pulled over the tarsal plate and released to lie on the tarsal plate. Then, the points of new attachments of levator muscle to the superior border of tarsus was marked. 
Three 6.0 Prolene sutures were used to fix the levator muscle to the anterior surface of the tarsus 2-3 $\mathrm{mm}$ from the upper tarsus border. The knot was secured with a slip knot initially. The eyelid was everted to assure that no penetration of the needle through conjunctiva occurs; if it does, the needle should be removed and repassed. Rechecking the lid level and contour, if ok, the slippery suture was released and converted to normal knot and tied. Then, lateral and medial to the first fixing suture, the same procedure was repeated to have 3 or 4 fixing points. Then, if the lid level was ok after rechecking (for those local anesthesia), the excess levator aponeurosis was excised. For those under general anesthesia, we depended on preoperative measures regarding the amount of levator resection. The skin was closed with several interrupted sutures, of which three carried into the levator to recreate the supratarsal crease. A Frost suture was placed. Eye ointment was applied, followed by mild compression dressing with cotton and fluffy gauze for 5-6 hours which was then replaced with steri strip plaster over the closed wound. Cold sponges were applied for the next 24 hours. All of the patients were examined 1 week, 1 month, 3 months, and 6 months after discharge. The outcome was defined as good if the lids were within $1 \mathrm{~mm}$ height with an acceptable skin crease and contour with no corneal exposure. A further group was identified with a suboptimal outcome, where there was more than $1 \mathrm{~mm}$ difference in lid height, and/or an asymmetric skin crease, and/or contour but who did not undergo further reoperation either because they did not want further surgery or wanted to delay until the child was mature enough to make his/her own decision. Another group was defined as poor if reoperation was required.

Ethical considerations: The study protocol was approved by Medical Ethics Committee of the Kurdistan Board of Medical Specialties. Informed consent was obtained from all parents (for children below 18 years old) and from the patients above that age.

Statistical analysis: Data were analyzed using the statistical package for social science (SPSS, version 25). The Chisquare test of associates was used to compare proportions. Fisher exact test was used when the expected count of more than $20 \%$ of the cells of the table was less than 5. A $P$ value of less or equal to 0.05 was considered statistically significant.

\section{Results}

This study included 53 patients (64 eyelids) with congenital blepharoptosis; 20 males and 33 females. The age of the patients ranged from 3 years to 54 years, with a mean age $\pm S D$ of $14.11 \pm 10.66$ years. The ptosis was right sided in 22 patients $(41.5 \%)$, left sided in 20 patients $(37.7 \%)$, and bilateral in 11 patients (20.8\%). The amount of levator resection according to the degree of ptosis is shown in Table 1. This shows that 19 (82.6\%)eyelids with severe ptosis underwent maximum levator resection, and most eyelids with mild ptosis underwent small resection. The table shows a significant association between ptosis degree and the amount of levator resection $(P<0.001)$.

Table 1: Degree of levator resection by the severity of ptosis.

\begin{tabular}{lcrrrrrrrr}
\hline \multirow{2}{*}{ Ptosis degree } & \multicolumn{2}{l}{ Levator resection } & \multicolumn{1}{l}{ Small } & \multicolumn{1}{c}{ Moderate } & \multicolumn{2}{c}{ Large } & Maximum & $\boldsymbol{P}$ value \\
\hline Mild Ptosis & 4 & $66.7 \%$ & 2 & $33.3 \%$ & 0 & $0.0 \%$ & 0 & $0.0 \%$ & \\
Moderate ptosis & 0 & $0.0 \%$ & 13 & $37.1 \%$ & 20 & $57.1 \%$ & 2 & $5.7 \%$ & \\
Severe ptosis & 0 & $0.0 \%$ & 1 & $4.3 \%$ & 3 & $13.0 \%$ & 19 & $82.6 \%$ & $<0.001$ \\
Total & 4 & $6.3 \%$ & 16 & $25.0 \%$ & 23 & $35.9 \%$ & 21 & $32.8 \%$ & \\
\hline
\end{tabular}


https:/ / doi.org/ 10.15218/ zjms.2021.002

Seventeen eyelids with severe ptosis and fair to poor levator function underwent maximum levator resection (Table 2), and 20 eyelids with moderate ptosis underwent large levator resection. All patients with small, moderate, and large levator resection had suboptimal to good satisfaction (Table 3 and Figure 3 ). Out of 53 cases, only six patients had poor satisfaction.

Table 2: Amount of levator resection according to the degree of ptosis and the amount of levator function.

\begin{tabular}{llcccc}
\hline $\begin{array}{l}\text { Ptosis } \\
\text { degree }\end{array}$ & $\begin{array}{l}\text { Levator } \\
\text { function }\end{array}$ & $\begin{array}{c}\text { Small levator } \\
\text { resection }\end{array}$ & $\begin{array}{c}\text { Moderate levator } \\
\text { resection }\end{array}$ & $\begin{array}{c}\text { Large levator } \\
\text { resection }\end{array}$ & $\begin{array}{c}\text { Maximum levator } \\
\text { resection }\end{array}$ \\
\hline Mild & Good & $4(66.67 \%)$ & $0(0.0 \%)$ & $0(0.0 \%)$ & $0(0.0 \%)$ \\
& Fair & $0(0.0 \%)$ & $2(33.33 \%)$ & $0(0.0 \%)$ & $0(0.0 \%)$ \\
& Poor & $0(0.0 \%)$ & $0(0.0 \%)$ & $0(0.0 \%)$ & $0(0.0 \%)$ \\
Moderate & Good & $0(0.0 \%)$ & $7(20 \%)$ & $3(8.57 \%)$ & $0(0.0 \%)$ \\
& Fair & $0(0.0 \%)$ & $2(5.71 \%)$ & $17(48.57 \%)$ & $0(0.0 \%)$ \\
& Poor & $0(0.0 \%)$ & $4(11.42 \%)$ & $0(0.0 \%)$ & $2(5.71 \%)$ \\
& Good & $0(0.0 \%)$ & $0(0.0 \%)$ & $0(0.0 \%)$ & $2(8.69 \%)$ \\
& Fair & $0(0.0 \%)$ & $1(4.34 \%)$ & $3(13.04 \%)$ & $9(39.13 \%)$ \\
& Poor & $0(0.0 \%)$ & $0(0.0 \%)$ & $0(0.0 \%)$ & $8(34.78 \%)$ \\
\hline
\end{tabular}

Table 3: The amount of levator resection versus patient satisfaction.

\begin{tabular}{lcccc}
\hline Levator resection & \multicolumn{3}{c}{ Patient satisfaction } \\
& Good & Suboptimal & Poor & Total \\
\hline Small levator resection & $4(100 \%)$ & $0(0.0 \%)$ & $0(0.0 \%)$ & $4(100 \%)$ \\
Moderate levator resection & $11(78.57 \%)$ & $3(21.42 \%)$ & $0(0.0 \%)$ & $14(100 \%)$ \\
Large levator resection & $15(88.23 \%)$ & $2(11.76 \%)$ & $0(0.0 \%)$ & $17(100 \%)$ \\
Maximum levator resection & $5(27.77 \%)$ & $7(38.88 \%)$ & $6(33.33 \%)$ & $18(100 \%)$ \\
Total & $35(66.03 \%)$ & $12(22.64 \%)$ & $611.32 \%)$ & $53(100 \%)$ \\
\hline
\end{tabular}
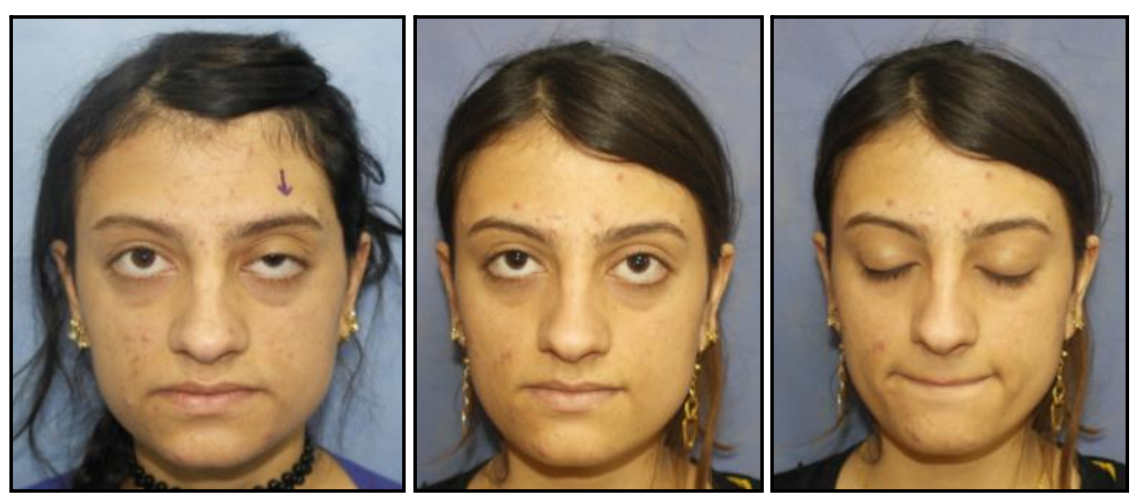

Figure 3: (Left) 19 years old patient with severe left congenital blepharoptosis. (Middle) 5 weeks after maximum levator resection shows good correction with patient satisfaction, (Right) post-operative during eye closure. 
https:// doi.org/ 10.15218/ zjms.2021.002

According to the type of anesthesia, out of 23 eyelids with severe ptosis, only four were done by local anesthesia (Table 4). In mild ptosis, out of 6 cases, three patients were operated on under local anesthesia.
Most of the cases had no complications post operatively (Table 5). Others had complications like lid lag, under correction, lagophthalmos, and over correction.

Table 4: Amount of levator resection in relation to the type of anesthesia and degree of ptosis.

\begin{tabular}{|c|c|c|c|c|c|c|}
\hline \multirow{2}{*}{$\begin{array}{l}\text { Ptosis } \\
\text { degree }\end{array}$} & \multirow{2}{*}{$\begin{array}{l}\text { Type of } \\
\text { anesthesia }\end{array}$} & \multicolumn{4}{|c|}{ Levator resection } & \multirow[b]{2}{*}{ Total } \\
\hline & & $\begin{array}{c}\text { Small } \\
\text { levator } \\
\text { resection }\end{array}$ & $\begin{array}{l}\text { Moderate } \\
\text { levator } \\
\text { resection }\end{array}$ & $\begin{array}{l}\text { Large } \\
\text { levator } \\
\text { resection }\end{array}$ & $\begin{array}{l}\text { Maximum } \\
\text { levator } \\
\text { resection }\end{array}$ & \\
\hline \multirow[t]{2}{*}{ Mild } & Local anesthesia & $3(75 \%)$ & $0(0.0 \%)$ & $0(0.0 \%)$ & $0(0.0 \%)$ & $3(4.68 \%)$ \\
\hline & General anesthesia & $1(25 \%)$ & $2(12.5 \%)$ & $0(0.0 \%)$ & $0(0.0 \%)$ & $3(4.68 \%)$ \\
\hline \multirow[t]{2}{*}{ Moderate } & Local anesthesia & $0(0.0 \%)$ & $1(6.25 \%)$ & $6(26.08 \%)$ & $0(0.0 \%)$ & $7(10.93 \%)$ \\
\hline & General anesthesia & $0(0.0 \%)$ & $12(75 \%)$ & $14(60.86 \%)$ & $2(9.52 \%)$ & $28(43.75 \%)$ \\
\hline \multirow[t]{2}{*}{ Severe } & Local anesthesia & $0(0.0 \%)$ & $0(0.0 \%)$ & $0(0.0 \%)$ & $4(19.04 \%)$ & $4(6.25 \%)$ \\
\hline & General anesthesia & $0(0.0 \%)$ & $1(6.25 \%)$ & $3(13.04 \%)$ & $15(71.42 \%)$ & $19(29.68 \%)$ \\
\hline
\end{tabular}

Table 5: Complications of levator resection.

\begin{tabular}{lcc}
\hline Complications & Frequency & Percent $(\mathbf{n}=\mathbf{5 3})$ \\
\hline No complication & 35 & 66.0 \\
Under correction & 3 & 5.7 \\
Lid lag & 11 & 20.8 \\
Lagophthalmos & 2 & 3.8 \\
Over correction & 2 & 3.8 \\
\hline
\end{tabular}
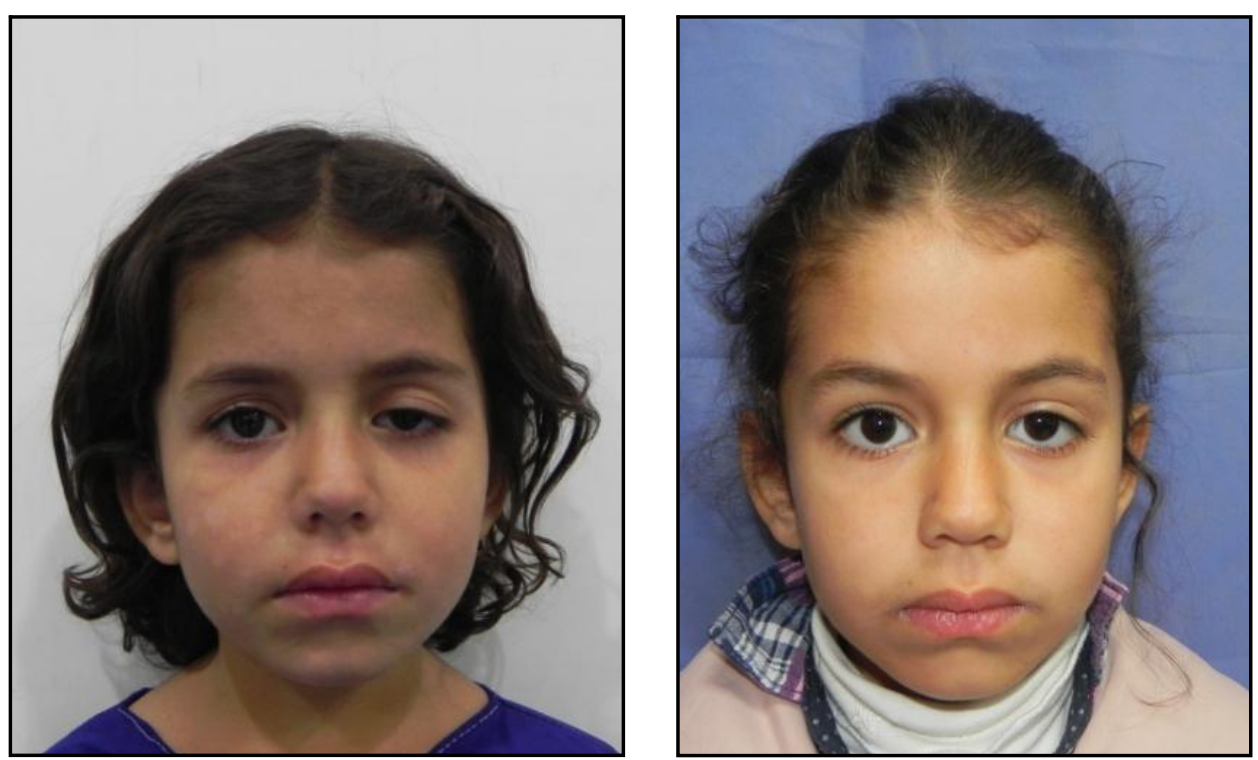

Figure 5: (Left) a case of severe left blepharoptosis, (Right) six months postoperative shows undercorrection. 


\section{Discussion}

Congenital ptosis is due to dysgenesis of the levator complex with the levator muscle being replaced by fatty and fibrous tissue. This dysfunction of the levator muscle gives rise to the classic triad of findings in congenital ptosis, including ptosis in the primary position, lagophthalmos in downgaze, and a poorly formed eyelid crease. ${ }^{8}$ Generally, in congenital ptosis, corrective surgery is delayed until the child is at least three years of age, allowing the anatomical structures of the eye to fully develop; however, the operation can take place earlier if needed. ${ }^{9}$ A variety of surgical procedures to correct congenital ptosis have been described. The choice of procedure depends on a number of patient-specific factors, such as degree of ptosis and levator function, as well as surgeon preference and resource availability. ${ }^{10}$ All of our patients were congenital ptosis, but most of them were above five years old during consultation because of delayed presentation. The surgical approaches and timing vary, depending on ptosis severity and levator function. Ptosis severity is categorized as mild $(<2 \mathrm{~mm})$, moderate $(3 \mathrm{~mm})$, or severe $\left({ }^{3} 4 \mathrm{~mm}\right)$. Levator function assessment is based on upper eyelid excursion and described as poor $(<4 \mathrm{~mm})$, fair $(5-7 \mathrm{~mm})$, or good $(>8 \mathrm{~mm})^{6}$ In congenital ptosis, according to $\mathrm{H}$. Hübner, effective levator advancement can be classified as follows; small $(10-13 \mathrm{~mm})$, moderate $(14-17 \mathrm{~mm})$, large $(18-22 \mathrm{~mm})$, maximum $(23 \mathrm{~mm})$, or more. ${ }^{11}$ In 21 cases of severe ptosis, 18 patients underwent maximum levator resection, and 12 cases showed suboptimal to good satisfaction. In 31 patients with moderate to large resection, all of them showed suboptimal to good satisfaction. Although Skaat et al. preferred frontalis sling as the only effective treatment for very severe ptosis or no levator function, we have used maximum levator resection for severe ptosis successfully in 16 patients with severe ptosis and fair to poor levator function.
The study shows a significant relationship between the amount of levator resection and patient satisfaction. The patient satisfaction rate was $88.68 \%$ of the cases, with only $11.32 \%$ of the cases were unsatisfied and requested revision surgery. Poor satisfaction was mainly associated with severe ptosis with poor levator function. Among the 53 patients with congenital ptosis, only 11 of operations were done under local anesthesia (Table 4) because most of the cases were in the pediatric age group who cannot tolerate operation under local anesthesia. Therefore, we regarded the preoperative assessment as a key factor in determining the amount of levator resection. For example, during preoperative assessment, if a patient presented with severe ptosis or poor levator function, our plan was to do maximum levator resection. For a patient with moderate ptosis and good levator function, the plan was moderate levator resection and so on. By comparing our results according to the type of anesthesia, we found no significant difference in the result, i.e., the preoperative plan was accurate. We agree with Ahmad and Della Rocca about the significance of preoperative evaluation. ${ }^{12}$ In our study, under correction $(5.7 \%)$ was more common than overcorrection $(3.8 \%)$. We think that under corrections were mainly due to inadequate resection of levator aponeurosis and loosening of sutures used to fix the levator aponeurosis to the tarsal plate. With the goal of creating as much postoperative symmetry as possible, surgery often has to be designed asymmetrically. When there is asymmetric ptosis, the plan should usually include asymmetric ptosis surgery. ${ }^{13}$ Lagophthalmosis defined as the inability to close the eyelids completely. This situation may lead to corneal problems such as epithelial defects, stromal thinning, exposure keratitis, bacterial infection, perforation, and blindness. ${ }^{14}$ In our study, lid lag was the most common complication (20.8\%). However, Alireza Abrishami et al. 
https:// doi.org/ 10.15218/ zjms.2021.002

concluded that undercorrection was the most common complication, which is a result similar to that found in previous reports. Reoperation can be effective in most cases.

\section{Conclusion}

The levator resection for congenital ptosis is effective even with poor levator function and replaced in our practice the traditional fascial sling. We recommend that further studies need to be done on a larger number of patients.

\section{Competing interests}

The authors declare no competing interests.

\section{References}

1. Lee JH, Nam SM, Kim YB. Blepharoptosis correction: levator aponeurosis-Müller muscle complex advancement with three partial incisions. Plast Reconstr Surg 2015; 135(2):388-95.

2. Hwang K. Surgical anatomy of the upper eyelid relating to upper blepharoplasty or blepharoptosis surgery. Anat Cell Biol 2013; 46(2):93-100.

3. Baldwin HC, Manners RM. Congenital blepharoptosis: a literature review of the histology of levator palpebraesuperioris muscle. Ophthal Plast Reconstr Surg 2002; 18(4):301-7.

4. Lin LK, Uzcategui N, Chang EL. Effect of surgical correction of congenital ptosis on amblyopia. Ophthal Plast Reconstr Surg 2008; 24(6):434-6.

5. Finsterer J. Ptosis: causes, presentation, and management. Aesthetic Plast Surg 2003; 27(3):193-204.

6. Skaat A, Fabian ID, Spierer A, Rosen N, Rosner M, Simon GJ. Congenital ptosis repair-surgical, cosmetic, and functional outcome: a report of 162 cases. Can J Ophthalmol 2013; 48(2):93-8.

7. Allard FD, Durairaj VD. Current techniques in surgical correction of congenital ptosis. Middle East Afr J Ophthalmol 2010; 17(2):129.

8. Keyhani K, Ashenhurst ME. Modified technique and ptosis clamp for surgical correction of congenital pediatric ptosis by anterior levator resection. Facial Plast Surg 2007; 23(03):156-61.

9. Harvey DJ, lamphongsai S, Gosain AK. Unilateral congenital blepharoptosis repair by anterior levator advancement and resection: an educational review. Plast Reconstr Surg 2010; 126(4):1325-31.

10. SooHoo JR, Davies BW, Allard FD, Durairaj VD. Congenital ptosis. Surv Ophthalmol 2014; 59(5):483-92.

11. Hübner $\mathrm{H}$. Kongenitale Ptosis. Klin Monatsbl Augenheilkd 2012; 229(01):16-20.
12. Ahmad SM, Della Rocca RC. Blepharoptosis: evaluation, techniques, and complications. Facial Plast Surg 2007; (03):203-15.

13. Lew H, Goldberg RA. Maximizing symmetry in upper blepharoplasty: the role of microptosis surgery. Plast Reconstr Surg 2016; 137(2):296e-304.

14. Tuna SH, Gumus HO, Hersek N. Custom-made gold implant for management of lagophthalmos: a case report. Eur J Dent 2008; 2:294.

15. Abrishami A, Bagheri A, Salour H, Aletaha M, Yazdani S. Outcomes of levator resection at tertiary eye care center in Iran: a 10-year experience. Korean J Ophthalmol 2012; 26(1):1-5. 